\title{
Um século de sífilis no Brasil: deslocamentos e aproximações das campanhas de saúde de 1920 e 2018/2019
}

\author{
Bruna Vanessa Dantas RIBEIRO ${ }^{1}$ \\ Roberta Cristina Barboza GALDENCIO ${ }^{2}$ \\ Elzimar Evangelista Peixoto PINTO $^{3}$ \\ Erika Drumond SARAIVA ${ }^{4}$ \\ Luisi Maria Costa de OLIVEIRA ${ }^{5}$
}

Resumo:

O artigo objetiva compreender, a partir do atual cenário epidêmico, os sentidos colocados em circulação sobre a sífilis na primeira campanha nacional realizada contra essa doença, em 1920, e na campanha de 2018/2019, de modo a explorar os possíveis deslocamentos, rupturas e aproximações nos sentidos mobilizados por ambas as campanhas. Via análise documental e de conteúdo, compara elementos de um corpus de doze materiais gráficos tratados pelas categorias de abordagem e endereçamento. Discute as funções das campanhas sanitárias, seu propósito de controlar doenças e ações informativas que desconsideram ações contínuas e especificidades locais. Reflete a lógica biomédica, as representações e construções discursivas e simbólicas que, apesar de tão díspares temporalmente, demonstram mais aproximações do que rupturas nas abordagens estratégicas e nos endereçamentos, constituindo, assim, um processo médico, político e social da sífilis no Brasil.

Palavras-chave: sífilis; campanhas de saúde; circulação de sentidos; análise documental.

\section{A century of syphilis in Brazil: displacements and approximations of the health campaigns of the 1920s and 2018/2019}

\begin{abstract}
:
The article aims to understand from the current epidemic scenario the meanings put into circulation about syphilis in the first national campaign against this disease, in 1920, and the 2018/2019 campaign, in order to explore possible displacements, ruptures and approximations in the meanings mobilized by both campaigns Through documentary and content analysis, it compares elements from a corpus of twelve graphic materials treated by the categories of approach and addressing. It discusses the functions of health campaigns, their purpose to control diseases and information actions that disregard continuous actions and local specificities. It reflects the biomedical logic, the discursive and symbolic representations and constructions that, despite being so different in time, demonstrate more similarities than ruptures in the strategic approaches and addresses, thus constituting a medical, political and social process of syphilis in Brazil.
\end{abstract}

Keywords: syphilis; health campaigns; circulation of meaning; document analysis.

${ }^{1}$ Mestre em Comunicação, Cultura e Cidadania, Universidade Federal de Goiás (UFG), Doutoranda em Informação e Comunicação em Saúde, Fiocruz/ICICT. E-mail: brunaribeirojor@gmail.com.

${ }^{2}$ Mestre em Ciência da Informação, UFF, Doutoranda em Informação e Comunicação em Saúde, Fiocruz/ICICT. E-mail: robegalrj@gmail.com.

${ }^{3}$ Mestre em Psicologia, UFES, Doutoranda em Informação e Comunicação em Saúde, Fiocruz/ICICT. E-mail: elzimarpeixoto@gmail.com.

\footnotetext{
${ }^{4}$ Mestre em Ciências, Fiocruz/ICICT. E-mail: erikadrumond@gmail.com.

${ }^{5}$ Mestre em Ciências, Fiocruz/ICICT. E-mail: luisi.costa43@gmail.com.
} 


\title{
Un siglo de sífilis en Brasil: desplazamientos y aproximaciones de las campañas de salud de 1920 y $2018 / 2019$
}

\begin{abstract}
Resumen:
El artículo tiene como objetivo comprender, desde el escenario epidémico actual, los significados puestos en circulación sobre la sífilis en la primera campaña nacional contra esta enfermedad, en 1920, y en la campaña 2018/2019, con el fin de explorar posibles desplazamientos, rupturas y aproximaciones en los sentidos movilizados por ambas campañas. A través del análisis documental y de contenido, compara elementos de un corpus de doce materiales gráficos tratados por categorías de abordaje y direccionamiento. Se analizan las funciones de las campañas de salud, su propósito de control de enfermedades y acciones de información que desconocen acciones continuas y especificidades locales. Refleja la lógica biomédica, las representaciones y construcciones discursivas y simbólicas que, a pesar de ser tan dispares en el tiempo, demuestran más similitudes que rupturas en enfoques y direcciones estratégicas, constituyendo así un proceso médico, político y social de la sífilis en Brasil.
\end{abstract}

Palabras clave: sífilis; campañas de salud; circulación de los sentidos; análisis de documentos

\section{Introdução}

Infecção sexualmente transmissível (IST), bacteriana, curável, que apresenta várias manifestações clínicas e diferentes estágios (primária, secundária, latente e terciária), a sífilis pode causar danos diversos, como cegueira, paralisia, doenças neurológicas e até a morte. Sua transmissão ocorre de pessoa para pessoa, por contato sexual, transfusão de sangue contaminado (menos comum) ou via transplacentária para o feto. Se não tratada, pode evoluir de forma crônica, apresentando períodos de atividade e de latência, recentes ou tardios. O diagnóstico é realizado por meio de teste rápido, disponível nas unidades de saúde, com leitura em 30 minutos, no máximo (BRASIL, 2019b).

Em 2016, o Ministério da Saúde, face ao aumento exponencial da sífilis no Brasil, decretou quadro de pandemia/epidemia, o que suscitou um amplo esforço nacional para o controle da doença, por meio de ações de saúde, entre elas, a realização de campanhas nacionais. Dados do Boletim Epidemiológico de Sífilis da Secretaria de Vigilância em Saúde apontam que em 2018 foram notificados 158.051 casos de sífilis adquirida (ou seja, disseminada por meio de relações sexuais); 62.599 casos de sífilis em gestantes; 26.219 casos de sífilis congênita; e 241 óbitos por sífilis congênita (BRASIL, 2019a). A redução desses números constitui um grande desafio para a saúde pública brasileira (BRASIL, 2019a).

O cenário epidêmico da década de 2010 a 2020 motiva este trabalho, que visa, por meio da análise de cartazes, filipetas e cartilhas, compreender os sentidos colocados em circulação 
sobre a sífilis, seus possíveis deslocamentos, rupturas e aproximações na primeira campanha nacional, realizada em 1920, e na campanha de 2018/2019.

Desde sua criação, no século XIX, as campanhas sanitárias são utilizadas como instrumentos de políticas públicas em saúde com o propósito de controlar determinada doença, com ações especializadas que buscam o esclarecimento e o apoio da sociedade e/ou profissionais de saúde sobre determinado tema de relevância para a saúde pública (SARACENI; LEAL; HARTZ, 2005).

Esta pesquisa tem como objetivo principal caracterizar os contextos históricos das campanhas de combate à sífilis da década de 1920 e de 2018/2019, identificar as estratégias por elas empregadas e discutir seus efeitos de sentidos. Para isso, abordamos o surgimento da sífilis no cenário mundial e a evolução conceitual da doença, um breve histórico da sífilis no Brasil e as funções das campanhas de combate à enfermidade realizadas pelas instituições públicas de saúde no país.

\section{O surgimento e a construção do conceito de sífilis}

O desenvolvimento da ideia de sífilis faz-se na Europa no final do século XV, em um contexto assolado por guerras, fome e outras catástrofes, culminando no acúmulo de epidemias e doenças. Sua origem é controversa: acredita-se que a sífilis tenha surgido nas regiões da Ásia, África meridional e América. Alguns estudos sobre a época apontam que a doença chega à Europa pelas grandes navegações no século XV (AZULAY, 1988). Já outros trabalhos defendem que a sífilis já estava presente na Europa há mais tempo, desde a Antiguidade, mas era confundida com outros patógenos (GOMES, 1974; MIRANDA, 2017; SANTOS FILHO, 1991). Quanto ao Brasil, sifilógrafos afirmam que, apesar da sua presença na América, a sífilis não existia no país no período pré-cabralino (CARRARA, 1997).

A guerra por conquistas territoriais foi vetor de propagação da sífilis, porém, a associação da doença com as relações sexuais ocorreu quando a enfermidade se alastrou em prostíbulos das cidades portuárias da Espanha e pelos portos europeus. A sífilis ganhou contornos pecaminosos e preconceituosos em razão do visual repulsivo, associando a doença a um castigo divino e aos comportamentos supostamente imorais da vítima (UJVARI, 2008).

Segundo Fleck (2010), até meados do século XIX, a construção conceitual referente à 
sífilis tinha fortes influências do princípio místico-ético dominante. Os cânones do pensamento astrológico, por exemplo, fomentaram a crença de que a epidemia venérea era um castigo divino aos pecados da luxúria. A esse respeito, é oportuno citar Carrara (1996):

O caráter ético da doença (castigo divino) fazia também da trajetória moral do doente ou de seu modo de vida elementos diagnósticos fundamentais. Inicialmente, como quase todas as epidemias, a sífilis circunscreveu uma espécie de responsabilidade coletiva (das mercantilistas cidades italianas e de toda uma Europa em pleno Renascimento). Depois, doença dos libertinos e das prostitutas, teria progressivamente passado a castigo mais individualizado, ao mesmo tempo em que adquiria feições mais endêmicas (CARRARA, 1996, p. 27).

Nos séculos posteriores, novas compreensões da sífilis surgiram, atreladas ao conceito biomédico. Carrara (1996) afirma que, a partir do final do século XIX, a reflexão médica sobre a sífilis passou por uma "revolução científica", com base em um modelo de compreensão da doença - seu agente causal, sintomas, meios de transmissão, medidas terapêuticas e profiláticas - que deu sustentação à chamada luta antivenérea. A descoberta do agente responsável pela sífilis, o Treponema pallidum, em 1905, em Berlim, por Fritz Richard Schaudinn e Paul Erich Hoffman, foi fundamental para esse processo (CARRARA, 1996).

De acordo com Avelleira e Bottino (2006), o século XX foi marcado pelo avanço da medicina e pelo surgimento de novas drogas. Esse cenário foi significativamente modificado com a introdução da penicilina para tratamento da doença a partir da década de 1940, que culminou com a diminuição da taxa de sífilis nos Estados Unidos da América (EUA) e, consequentemente, provocou a diminuição do estudo e controle da doença (SARACENI; LEAL; HARTZ, 2005; AVELLEIRA; BOTTINO, 2006).

A partir da década de 1960, ressaltam Avelleira e Bottino (2006), as mudanças ocorridas na sociedade com relação ao comportamento sexual, com o advento da pílula anticoncepcional, resultaram no aumento de casos de sífilis desassociado do aspecto estigmatizante da doença, visto que tinha tratamento. Ainda segundo os autores, no final da década de 1970, porém, com o aparecimento da síndrome da imunodeficiência adquirida (Aids), houve um redimensionamento das doenças sexualmente transmissíveis. O papel da sífilis como fator facilitador na transmissão do vírus HIV ocasionaria novo interesse da medicina e da ciência pela doença e a necessidade de estratégias para seu controle. 


\section{A sífilis no Brasil e suas campanhas}

No Brasil, Gomes (1974) aponta que os jesuítas foram os primeiros a identificar a disseminação da doença, no século XVI, após a chegada dos portugueses ao país. Contudo, as ações para eliminá-la no país só foram iniciadas em 1901, com a criação da Sociedade para a Profilaxia Moral e Sanitária. Décadas depois, em meio a uma fase de grande intervenção estatal nos problemas nacionais de saúde, a criação do Departamento Nacional de Saúde Pública (DNSP) e da Inspetoria de Profilaxia da Lepra e das Doenças Venéreas, por meio da Lei n⿳⺈ 3.987, de 2 de janeiro de 1920 (BRASIL, 1920), significou a expansão das ações de cunho preventivista e a centralização de medidas profiláticas das doenças transmissíveis no país. Foi nesse momento que ocorreu a primeira campanha contra a sífilis no Brasil (SARACENI; LEAL; HARTZ, 2005).

Segundo Carrara (1996), no final do século XIX e o início do XX foram marcados por grande incidência de sífilis no Brasil. Estima-se que, de 1920 a 1940, cerca de um quinto da população brasileira tenha sido contaminada pela doença. Não há números exatos nesse período, pois a notificação de casos não era obrigatória, o que não impedia médicos de denunciar uma possível epidemia. O autor afirma que essas denúncias baseavam-se nas experiências clínicas dos profissionais, em dados oferecidos pela população hospitalizada e no senso comum. Em 1921, na primeira palestra educativa da Inspetoria de Profilaxia da Lepra e das Doenças Venéreas, Renato Kehl (apud CARRARA, 1996), com base em estimativas de sifilógrafos, afirmou que existiam no Brasil naquele momento seis milhões de pessoas contaminadas pela sífilis, contabilizando $20 \%$ da população.

No início da década de 1960, houve declínio da incidência da sífilis em decorrência da descoberta de novos medicamentos. A redução dos casos, todavia, não se deu por muito tempo, posto que havia o desinteresse das autoridades pelo controle das doenças venéreas, poucos estudos realizados por novas gerações de médicos sobre as doenças infecciosas, também chamadas de sociais, além do desconhecimento por parte do público e da falta de educação sanitária (GONTIJO; ANTONIO, 2016).

Mais de cem anos depois da primeira campanha contra a sífilis, o país torna a enfrentar expressivo aumento no número dos casos da enfermidade (BRASIL, 2019a). Responder ao 
aumento de casos de sífilis exige uma abordagem multifatorial, que consiste no fortalecimento e ampliação do acesso ao Sistema Único de Saúde (SUS) por meio das ações de prevenção, aumento de insumos para testagem, medicação para o tratamento aliada ao treinamento adequado dos profissionais de saúde. Uma das dificuldades relatadas por profissionais de saúde é a baixa adesão ao tratamento, devida a barreiras culturais e socioeconômicas, visto ser uma terapêutica longa e por vezes dolorida, o que prejudica a identificação do estágio e de formas de lidar com a doença (FIGUEIREDO; CAVALCANTE; OLIVEIRA; MONTEIRO; QUIRINO; OLIVEIRA, 2015).

No que diz respeito às campanhas de saúde pública no Brasil, Araújo e Cardoso (2014) lembram que, desde a década de 1920, o modelo de saúde dominante tinha na propaganda uma importante forma de enfrentamento das doenças no país. Com relação às suas funcionalidades, no entanto, é possível verificar algumas discrepâncias. Seu papel estratégico é incontestável, mas há estudos que mostram o quanto são limitadas. De acordo com Albarado, Prado e Mendonça (2019), as campanhas privilegiam anúncios informativos em diferentes ações de prevenção, mas há necessidade de utilizar estratégias complementares e considerar alternativas e especificidades locais.

\section{Metodologia}

Em termos metodológicos, foi realizada uma pesquisa comparativa, de abordagem qualitativa, utilizando a análise documental como amparo teórico para compreensão e estudo das campanhas. Tomamos como corpus de análise doze materiais gráficos, entre anúncios, folhetos, cartazes e panfletos, produzidos para as campanhas sobre sífilis em 1920 e 2018/2019, a fim de obter um intervalo temporal significativo para uma análise comparativa dos conteúdos. Os materiais têm em comum sua natureza de impressão gráfica, o que, apesar das diferenças entre formatos, permite aproximações entre ambos os conjuntos.

Os cartazes e folhetos da campanha de $1920^{6}$ foram consultados no Departamento de Arquivos e Documentação da Casa de Oswaldo Cruz (DAD-COC) e fazem parte do acervo do médico Renato Ferraz Kehl, que organizou o Serviço de Educação Sanitária ligado à Inspetoria

\footnotetext{
${ }^{6}$ As peças da campanha de 1920 não estão disponíveis on-line. As imagens analisadas são fotografias realizadas no Departamento de Arquivos e Documentação da Casa de Oswaldo Cruz (DAD-COC).
} 
da Lepra e das Doenças Venéreas. Na campanha de 2018/2019 houve peças publicitárias de vários formatos. Para a análise comparativa, optamos por peças impressas em formato de cartazes e anúncios da campanha "Sífilis Não", de 2018/2019, disponibilizados no site da campanha (BRASIL, 2018).

O critério de escolha foi a natureza documental, igual à encontrada no material da campanha de 1920, ou seja, o fato de se tratar de peças impressas. A campanha mais recente foi realizada pelo Ministério da Saúde em parceria com a Universidade Federal do Rio Grande do Norte (UFRN) e a Fundação Norte-Rio-Grandense de Pesquisa e Cultura (Funpec). O recorte do corpus justifica-se na ideia de que uma comparação permite compreender a construção e a mudança da representação da sífilis nas peças institucionais governamentais considerando as diferenças históricas, culturais e nos modos de vida.

Para tratamento do material coletado, foi utilizada a técnica de análise de conteúdo, que propõe a organização do material por meio da pré-análise; exploração do material; tratamento dos resultados, inferência e interpretação (BARDIN, 2011). A exploração do material levou à organização da análise por meio das categorias "estratégias de abordagem" e "endereçamento". As estratégias de abordagem compreendem a forma de organização da campanha, bem como suas temáticas e representações centrais. $\mathrm{O}$ endereçamento diz respeito a quem a campanha é direcionada e aos públicos que pretende alcançar.

$\mathrm{Na}$ etapa de tratamento dos resultados, as categorias definidas foram utilizadas para agrupá-los com os mesmos recortes temáticos, a fim de estabelecer correlações nas análises. Essas aproximações nortearam os processos de inferência e interpretação que buscaram estabelecer uma relação entre os materiais, tornando possível realizar uma análise comparativa dos conteúdos e das questões sociais e históricas que envolvem a compreensão da sífilis nas duas épocas analisadas.

\section{Estratégias de abordagem}

A campanha realizada em 1920 utilizou como estratégia de abordagem o medo e o sentimento de nacionalismo, vinculando a sífilis ao universo das doenças venéreas e, consequentemente, ao movimento denominado "luta antivenérea". Nesse sentido, a sífilis e outras afecções associadas eram percebidas como o "mal" que deveria ser enfrentado, para 
garantir o bem-estar individual e da nação (CARRARA, 1997). O discurso presente em 1920 focaliza a identificação da doença por meio dos sintomas, do alarde em torno das possíveis consequências da sífilis não tratada e da busca por tratamento, como é possível ver na Figura 1: “A Syphilis e outras doenças venereas podem causar males irremediaveis como sejam: loucura, paralysia, doenças do coração, cegueira, rheumatismo, endurecimento das juntas".

Os materiais traziam uma lógica educativa atrelada ao discurso alarmante, bem como um discurso higienista, de controle dos corpos e comportamentos. Discurso que se sustenta na premissa de que o controle, a vigilância e a normatização das massas são os elementos que vão garantir o controle das epidemias (FOUCAULT, 1979).

Figura 1- "A Syphilis e outras doenças Venereas podem causar males irremediaveis como sejam:"

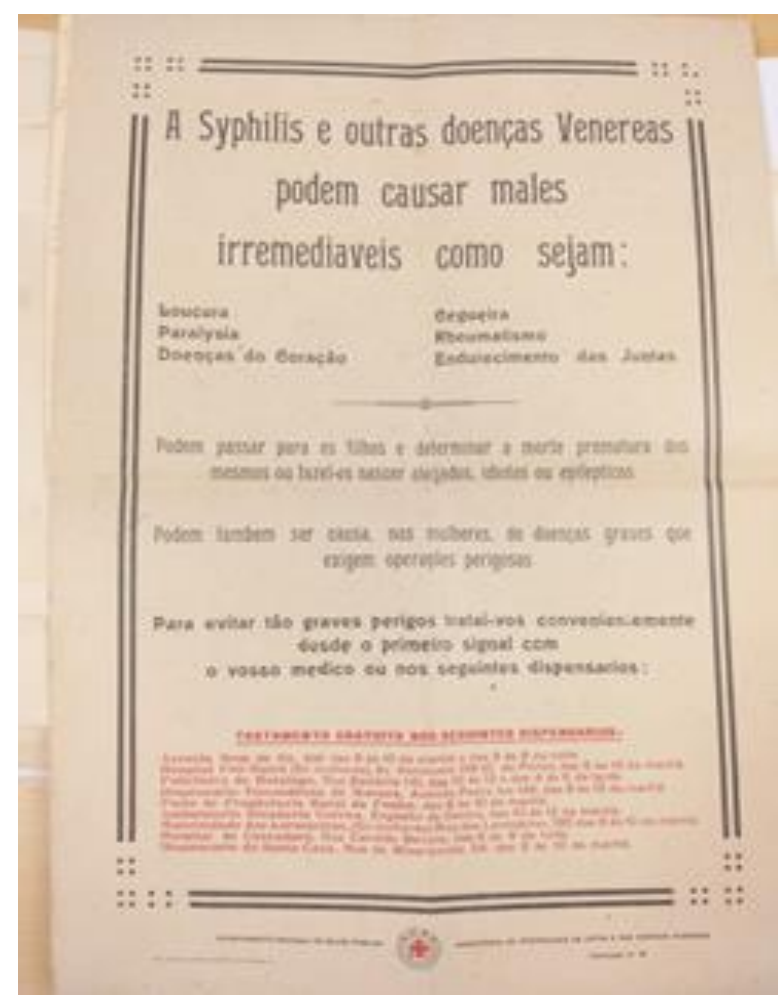

Fonte: Fundação Oswaldo Cruz (2009).

A prática do controle e da vigilância foram algo comum em diversas campanhas desenvolvidas pelo Departamento de Saúde Pública, caracterizando as ações realizadas no início do século XX. Pode-se afirmar que a sífilis, considerada naquele período uma doença da desinformação ou da ignorância, permitiu uma prática social impregnada pelos preceitos 
higienistas e eugênicos que permeavam todas as esferas do cotidiano dos indivíduos, como a educação, o trabalho e a família. Influenciados pelo discurso higienista, os títulos das Figuras 2 e 3, "Cuidado com as doenças venereas" e "Em sofrimento e mortes", transmitiam noções de proteção contra a doença por meio do medo.

Figura 2 - "Cuidado com as doenças venereas"

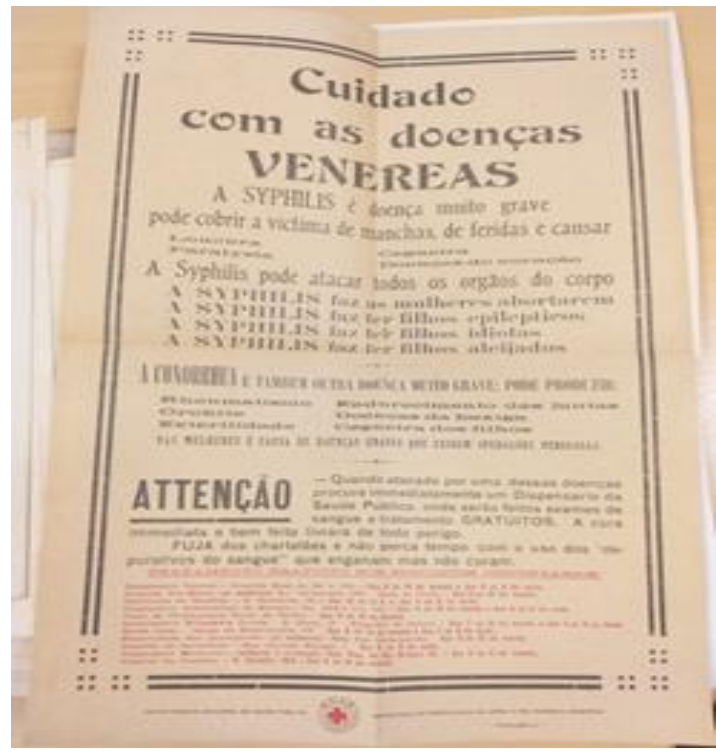

Fonte: Fundação Oswaldo Cruz (2009).
Figura 3 - "Em soffrimentos e mortes"

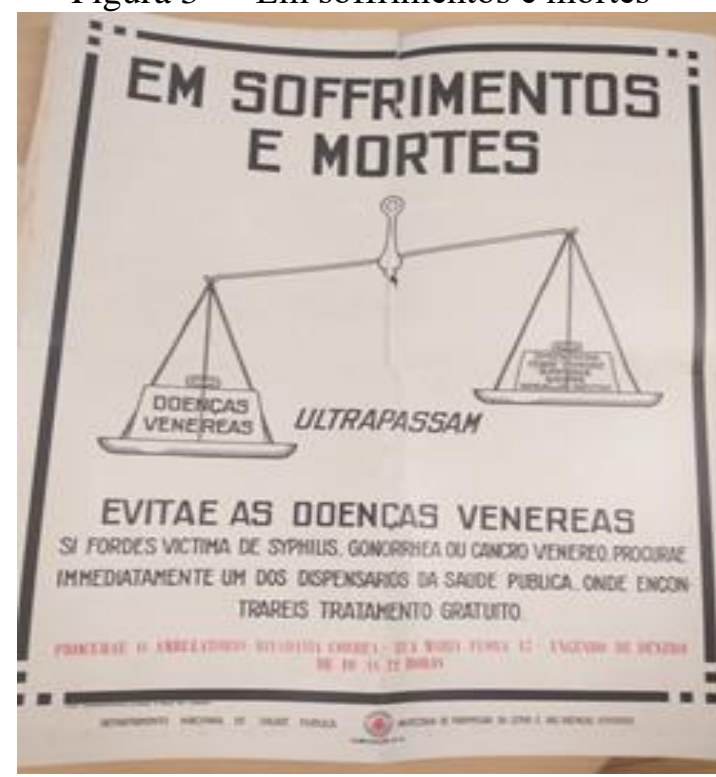

Fonte: Fundação Oswaldo Cruz (2009).

É importante destacar que as primeiras campanhas possuíam caráter preventivo e educativo e tinham a intenção de criar uma consciência sanitária na população. Araújo e Cardoso (2014, p. 42) assinalam: "Não é de se surpreender, então, que a educação e comunicação tenham passado a ser associadas fortemente à implantação das políticas públicas em saúde”. Segundo as autoras, utilizando-se da pedagogia civilizatória baseada em educar, higienizar e sanear, as ações ignoravam os determinantes sociais das doenças e confiavam à educação dos indivíduos a superação do atraso e a instalação de condições mais propícias ao progresso e à ordem.

A perspectiva nacionalista é um fator importante na estratégia de abordagem da campanha. O combate à sífilis é colocado como um desafio de todos, como finalidade do bemestar coletivo. Como mostra a Figura 4, a prevenção e o tratamento são vistos como atos de patriotismo, sendo um dever do cidadão brasileiro. Essa percepção converge com questões comuns na comunicação pública brasileira daquele período: além de reforçar o medo e o risco 
do contágio, são excluídos os determinantes sociais e culpabilizadas as pessoas pelas situações de emergência pública.

Figura 4 - "As doenças venereas ameaçam a saude do nosso povo"

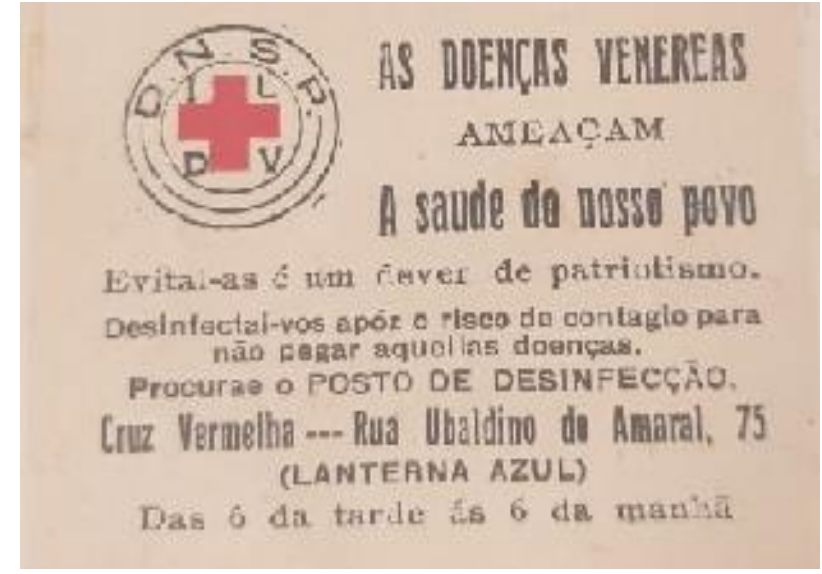

Fonte: Fundação Oswaldo Cruz (2009).

Como explica Carrara (1996), no início do século XX o combate a sífilis mostrava-se como um ponto de apoio para o desenvolvimento de ideais nacionalistas carregados de prognósticos favoráveis. É nesse cenário que se constroem simultaneamente os conceitos de sífilis-inimiga e nação brasileira:

Quando se tratava de "salvar" a nação, centrar a atenção na sífilis (como, aliás, em outras doenças endêmicas e epidêmicas que assolavam o país) já espelhava uma postura mais nacionalista, pois significava colocar em xeque a ideia de que estaríamos fadados a sermos para sempre uma nação incivilizada, atrasada, dependente etc. (CARRARA, 1996, p. 290).

Trazendo para o momento atual, a campanha de 2018/2019, por sua vez, ainda que dentro de uma abordagem biomédica, evidencia uma tentativa de maior aproximação com o público por meio de uma linguagem acessível. Apesar de algumas mudanças na abordagem, ainda é perceptível o foco no comportamento individual para o controle da doença. Nesse cenário, permanece o distanciamento dos determinantes sociais da saúde, como apontam Araújo e Cardoso (2014), já que o modelo biomédico centraliza a doença e distancia o paciente do seu processo de adoecimento.

Se, por um lado, vemos uma diferença na forma como o discurso da prevenção se constrói, por outro, vemos um resgate da lógica nacionalista utilizada na campanha de 1920. 
Apesar do foco no comportamento individual, nos materiais de 2018/2019, ainda é possível perceber uma estratégia de abordagem que destaca o coletivo, como na frase "O Brasil pode vencer a sífilis, faça sua parte”, encontrada na Figura 5. Em contradição com ideologias que priorizam o indivíduo, as campanhas de saúde pública ainda são um espaço para pensar a nação e a seu respeito falar. Em consonância, porém, com a abordagem de culpabilização, o coletivo se sobrepõe ao individual, e o indivíduo se torna responsável por defender o seu país buscando tratamento. A mensagem é clara, é possível superar todos os limites e salvar o país, por meio das ações individuais, transformando o sujeito em herói ou culpado em relação à doença.

Figura 5 - "O Brasil pode vencer a sífilis"

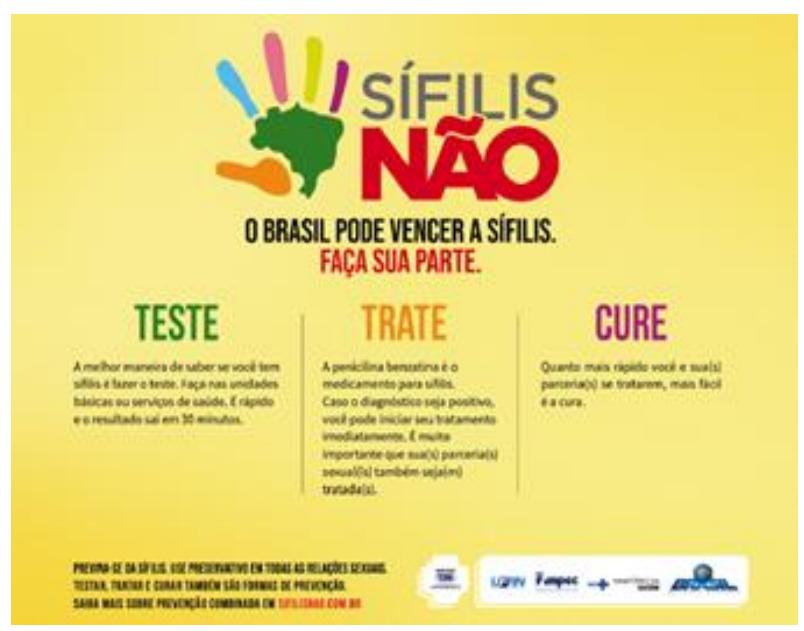

Fonte: Brasil (2018).

Como é possível ver na Figura 5, com caráter informativo e educativo, a campanha atual amplia o discurso para três pilares: teste, tratamento e cura - três processos individuais, porém com consequências também coletivas, que devem ser consideradas pelo cidadão. Ela se diferencia daquela realizada em 1920 por dar menos destaque às consequências de uma infecção não tratada, ao ressaltar a importância de realização do teste, independentemente dos sintomas, e ao enfatizar a simplicidade e rapidez do diagnóstico e do tratamento. A mensagem é: faça o teste, o resultado é rápido, o tratamento é seguro, é possível se curar. Nesse sentido, a Figura 5 traz frases como "Para saber se você tem faça o teste", "O resultado sai em até 30 minutos" e "O teste deu positivo? Faça logo o tratamento".

É interessante destacar que na sociedade contemporânea as pessoas são encorajadas a cuidar da própria saúde, visando à otimização corporal e comportamental, bem como ao 
aumento da performance e à normalização dos corpos. As peças de divulgação evidenciam a estratégia de responsabilização do indivíduo, que se torna encarregado de seu diagnóstico e cura. A abordagem, no entanto, pode gerar um processo de culpabilização para os indivíduos que não conseguem seguir o tratamento recomendado. Novamente, as questões sociais e subjetivas são desconsideradas, e a resolução do problema recai sobre o indivíduo, seja para se afastar da doença por meio da redução de práticas sexuais, seja pela responsabilização por seu diagnóstico e tratamento.

Percebe-se que, apesar do intervalo de cem anos entre a duas campanhas analisadas, ambas disseminam vozes autorizadas que ensinam à população hábitos e condutas de saúde, desconsiderando seus conhecimentos, experiências e desejos, promovendo, assim, o apagamento da polifonia social. A análise aqui empreendida corrobora a colocação de Albarado, Prado e Mendonça (2019, p. 77) de que entre os fatores limitantes das campanhas em saúde estão: "a falta de representatividade no que se refere às imagens, linguagem, personagens e locais escolhidos; superficialidade e rapidez dos materiais produzidos devido ao alto custo para veiculação; a forma transmissiva e verticalizada das informações, entre outros”.

\section{Endereçamento}

Tendo como base a moralidade monogâmica heteronormativa, a campanha de 1920 é voltada para a saúde de homens casados e a possibilidade de transmitir a doença para sua família, sendo ele o único responsável pela prevenção da doença. Dessa forma, as orientações dadas na campanha visam à figura masculina. Carrara (1996) afirma que as campanhas antivenéreas do início do século XX tinham como foco o comportamento sexual masculino heterossexual. A homossexualidade não é mencionada porque abriria margem para que concepções em voga sobre a masculinidade fossem questionadas e, consequentemente, seu acesso às mulheres, o que, para o autor, atingia pontos cruciais dos poderes oligárquicos e patriarcais que controlavam a sociedade da época (CARRARA, 1996).

A campanha de 1920 atrelava o contágio da sífilis às relações sexuais extraconjugais $\mathrm{e}$ com profissionais do sexo, como é possível perceber no texto presente em uma das peças: “A syphilis é doença muito grave e muito generalizada, quase sempre adquirida nas relações sexuaes extra-conjugaes e principalmente com prostitutas públicas ou clandestinas...". E 
adiante: "A syphilis mal curada póde ser transmitida a outra pessoa, como à esposa e aos filhos". O trecho destacado, presente na peça reproduzida na Figura 6, traz implícita a mensagem de que a sífilis era, em geral, introduzida na família por intermédio do homem em decorrência de comportamento sexual moralmente inaceitável, posto que coloca todos em risco. A partir disso, evitar o contato com a prostituição era tida como medida profilática de combate à doença.

$\mathrm{Na}$ referida peça encontramos a seguinte afirmação: "O meio mais seguro de não apanhar syphilis, gonorrhea ou cancro venereo é fugir das prostitutas [em vermelho] e, em geral, das relações extra-conjugaes". No entanto, essa moralidade admite que ele, homem, supra as necessidades, e adverte que se o homem precisar se encontrar com prostitutas, deve tomar os devidos cuidados. Algumas peças apresentam "conselhos para homens", elencando uma série de procedimentos a seguir, caso o homem não possa evitar as relações sexuais com profissionais do sexo, como podemos ver na Figura 6.

Figura 6 - "Meios de evitar as doenças venereas"

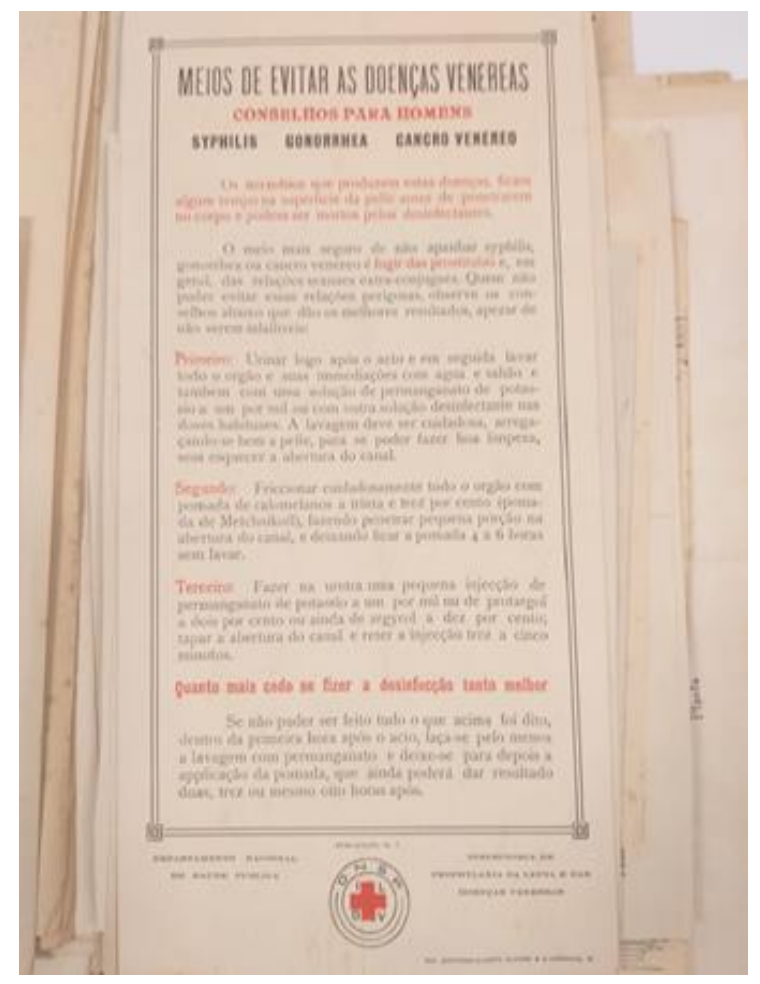

Fonte: Fundação Oswaldo Cruz (2009). 
O debate acerca da sífilis que surge na década de 1920 é permeado pela defesa da ideia de uma hipersexualidade do brasileiro por parte dos sifilógrafos do país, que vão enfatizar:

a influência que fatores sociomorais - ignorância, pobreza, imoralidade do meio social, herança escravocrata etc. - teriam sobre a "necessidade sexual", produzindo os excessos. Condicionando a intensidade, constância e diversificação da demanda e da oferta no mercado sexual, tais fatores determinariam, em última instância, o ritmo de difusão da sífilis no país (CARRARA, 1997, p. 403-404).

Logo, era frequente a menção à defesa da família e ao comportamento sexual socialmente aceitável. Parece-nos que as práticas de sexualidade, a concepção de família e o biopoder (FOUCAULT, 2008) para garantir a regulação da população permeiam as ações do campo da saúde e, como tal, estão presentes tanto na campanha de 1920 quanto na de 2018/2019.

As prescrições e o poder médico, construídos por meio da norma disciplinar, estão claramente presentes na campanha e nas orientações veiculadas em 1920, apontando que o indivíduo que estivesse infectado com a bactéria causadora da sífilis não se poderia casar antes de prévio tratamento médico. Outras peças sugerem que a doença pode ser adquirida de forma "inocente" pelo uso comum de objetos contaminados, porém, o maior destaque das peças em geral é a questão sexual atrelada à fidelidade e aos comportamentos sexuais socialmente aceitáveis.

A questão moral, apontada por Carrara (1997), também é evidenciada pela exclusão das profissionais do sexo do público-alvo da campanha. O discurso as trata de forma genérica, “essas mulheres”, incorrendo, por um lado, em culpabilização e, por outro, em invisibilidade dessas profissionais - apontadas ao longo da campanha como as responsáveis pela proliferação da doença e infecção nas famílias. Em nenhum momento, porém, dirige-se a elas informações sobre a doença, o diagnóstico e o tratamento.

Nesse sentido, a campanha não é endereçada às mulheres e, quando as evoca, concebeas apenas como membros de uma família ou como prostitutas. A falta de orientação específica às mulheres se verifica mesmo em casos nos quais elas eram diretamente responsáveis pela transmissão. Na década de 1920, por exemplo, já se sabia que a sífilis podia ser transmitida de mãe para o filho durante a gravidez. No entanto, as campanhas que abordavam o tema não eram 
endereçadas às grávidas, como é possível observar na Figura 1. Ao contrário, tinham como foco principal a proteção à família como instituição e símbolo de prosperidade, alertando quanto às possíveis consequências da doença para os filhos. A partir dessa perspectiva, e utilizando como argumento as possíveis consequências da doença para os filhos, a campanha alia a importância da prevenção e o tratamento da sífilis à proteção da família como instituição e símbolo da prosperidade.

As frases "As doenças venereas são as maiores causas de morte e deformidade dos filhos" e "O futuro dos syphilicos e de sua descendência depende do tratamento precoce e prolongado da doença" retiradas de uma cartilha e uma filipeta, respectivamente, permitem a interpretação do modo como a família aparece na campanha, fazendo parte de argumentos eugênico e higienista, que pretendem "limpar" o país, evitando doentes mentais e deficientes físicos, frutos de doenças venéreas.

Na campanha de 2018/2019 o discurso da família também está presente, mas se desenha de outra forma, sendo atrelado à gravidez e ao combate à sífilis congênita. Há o endereçamento a mulheres grávidas, com a elaboração, inclusive, de duas peças específicas sobre a sífilis congênita (Figura 7). Posteriormente, foi realizada uma campanha exclusiva sobre o tema. Nesses materiais, não há um discurso direto de culpabilização de profissionais de sexo ou responsabilização dos homens pela transmissão da infecção à parceira e, consequentemente, sua introdução no interior da família.

Um ponto de convergência entre as duas campanhas é a alusão unicamente a práticas sexuais heterossexuais, já que tanto a campanha de 1920 quanto a de 2018/2019 não citam relações homoafetivas. Com relação à faixa etária, a campanha de 1920 não é específica, mas o destaque dado à não transmissão da doença aos filhos permite entender que se endereçava a casais em idade reprodutiva. A campanha de 2018 é endereçada tanto a pessoas casadas quanto a solteiras, na maioria das vezes jovens, como evidenciam os personagens da Figura 8. Isso ocorreu porque, segundo o Boletim Epidemiológico de 2019, com base nos dados fornecidos pelo Sistema de Informação de Agravos de Notificação (Sinan), as mais altas taxas de detecção de sífilis adquirida no Brasil, de 2010 a 2018, foram registradas em pessoas nas faixas etárias de 20-29 anos e 30-39 anos (BRASIL, 2019a). 
Figura 8 - "Lembre de se cuidar. Sífilis: teste, trate e cure"

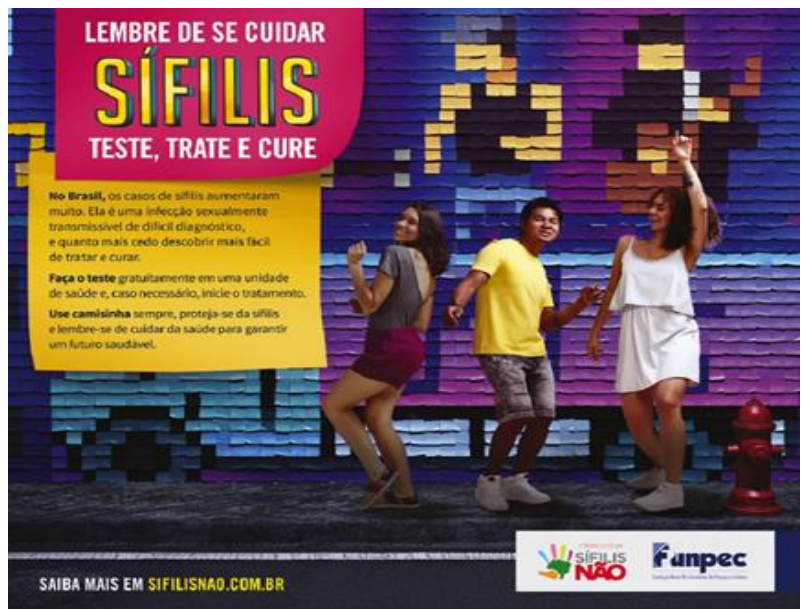

Fonte: Brasil (2018).

No geral, as peças de 2018/2019 trazem uma série de personagens: homens e mulheres jovens, mulheres grávidas, de forma que a prevenção contra a sífilis é orientada para público diversificado, cabendo a prevenção tanto ao homem quanto à mulher, como, por exemplo, na citação sobre "camisinhas" feminina e masculina. Ou seja, a campanha é direcionada a grupos que socialmente são considerados aptos a ter vida sexual ativa. A campanha busca mostrar diversidade por meio dos modelos fotografados, porém, textualmente não diferencia gênero, classe, raça ou qualquer outro determinante, não incluindo os fatores sociais, econômicos, políticos, entre outros, que podem influenciar o processo de adoecimento.

\section{Considerações finais}

O trabalho aqui empreendido estabeleceu uma análise comparativa entre materiais gráficos de campanhas de combate à sífilis da década de 1920 e de 2018/2019. Essas comparações produziram inferências acerca de estratégias, contextos históricos e sentidos que tais ações colocam em circulação na sociedade, em duas categorias: estratégias de abordagem e de endereçamento. Com base nessas categorias buscamos estabelecer relações, padrões ou divergências entre as duas campanhas, de forma que algumas questões se mostraram centrais: o medo como discurso, o combate à doença como uma questão patriótica, a individualização de condutas e as construções morais acerca da sexualidade e da família.

A categoria estratégias de abordagem evidencia que a primeira campanha (1920) utiliza o medo como uma estratégia de conscientização da população para os efeitos maléficos da 
doença. A categorização da sífilis como doença venérea a coloca como um "mal" que deve ser combatido a fim de proteger a nação e a saúde da família. A correção do comportamento desviante objetiva a volta do doente ao seu estado de normalidade e ao sistema produtivo. $\mathrm{O}$ discurso utilizado nos materiais era biomédico e higienista, baseado no lema "educar, higienizar e sanear" (pedagogia civilizatória). Na campanha de 2018, há mais aproximação com o público, por meio de um discurso didático. O medo como estratégia se desloca das possíveis consequências da doença para as pessoas e seus filhos para o destaque no aumento do número de casos.

Em um cenário em que a evolução da medicina permitiu que o diagnóstico, o tratamento e a cura se tornassem simples, rápidos e gratuitos, na campanha de 2018/2019 permanece a ideia de uma luta coletiva contra a doença, porém é fortalecida a responsabilização do indivíduo sobre sua saúde. Uma vez que a falta de acesso ao tratamento não é considerada e que o diagnóstico ou a cura podem não ser alcançados por todos, essa responsabilização possibilita uma culpabilização de populações vulneráveis.

Com relação à categoria endereçamento, inferimos uma mudança significativa nos públicos que essas campanhas buscavam alcançar, passando de homens casados em idade reprodutiva para jovens adultos em geral. Na campanha de 1920 não havia referência a indivíduos solteiros. E as mulheres grávidas, mesmo dando-se grande destaque às consequências das doenças para os filhos de indivíduos infectados. Em 2018/2019, a campanha é voltada para o público jovem, não havendo uma especificação quanto ao estado civil. Essas mudanças decorrem dos recentes números de contágio de sífilis no país, que mostram aumento da doença entre indivíduos de 20 a 39 anos (BRASIL, 2019a). O crescimento dos números de sífilis congênita redesenhou o endereçamento da campanha de 2019, já que várias peças são hoje direcionadas às mulheres grávidas.

Em ambas as categorias de análise foi possível perceber a centralidade da família e da sexualidade, permeadas pela moral. Percebemos que ocorreu uma mudança significativa na forma como os temas foram abordados ao longo de cem anos no Brasil, entretanto é visível a permanência do viés moral no discurso. Na campanha de 1920, o contágio era atrelado ao sexo extraconjugal de homens com mulheres profissionais do sexo, relações essas que colocavam em risco a saúde da família, mas não à família enquanto instituição, já que se compreende uma 
certa inevitabilidade da quebra do contrato monogâmico por parte dos homens. Na campanha de 2018/2019, o discurso não liga somente o homem ao contágio, podendo o mesmo ocorrer em consequência de diversos tipos de relação. A família, contudo, ainda tem grande importância.

Este trabalho buscou compreender as campanhas de 1920 e 2018/2019 como frutos de seu tempo. Além de refletir a lógica biomédica que rege o diagnóstico e o tratamento da sífilis no Brasil, essas campanhas também carregam as compreensões políticas e sociais que permeavam o país no momento de sua circulação. Mais do que uma reflexão acerca das imagens e textos de forma isolada, procuramos apreender os sentidos e construções discursivas e simbólicas que, apesar de tão díspares temporalmente, demonstram mais aproximações do que rupturas nas abordagens estratégicas e endereçamentos, constituindo, assim, um processo médico, político e social da sífilis no Brasil.

\section{Referências}

ALBARADO, Adria Jane; PRADO, Elizabeth Jesus; MENDONÇA, Ana Valéria Machado. Um, dois, três - gravando: as campanhas audiovisuais do ministério da saúde sobre dengue, chikungunya e zika de 2014 a 2017. Revista Eletrônica de Comunicação, Informação e Inovação em Saúde, Rio de Janeiro, v. 13, n. 1, p. 75-86, 2019. Disponível em: https://www.reciis.icict.fiocruz.br/index.php/reciis/article/view/1596. Acesso em: 25 set. 2020.

ARAÚJO, Inesita Soares de; CARDOSO, Janine Miranda. Comunicação e saúde. Rio de Janeiro: Fiocruz, 2014.

AVELLEIRA, João Carlos Regazzi; BOTTINO, Giuliana. Sífilis: diagnóstico, tratamento e controle. Anais Brasileiros de Dermatologia, Rio de Janeiro, v. 81, n. 2, p. 111-126, 2006. Disponível em:

https://www.scielo.br/j/abd/a/tSqK6nzB8v5zJjSQCfWSkPL/abstract/?lang=pt. Acesso em: 27 set. 2020.

AZULAY, Rubem David. História da sífilis. Anais Brasileiros de Dermatologia, Rio de Janeiro, v. 3, n. 1, p. 3-4, jan.-fev. 1988. Disponível em:

http://www.anaisdedermatologia.com.br/sumario/265. Acesso em: 16 set. 2020.

BARDIN, Laurence. Análise de conteúdo. São Paulo: Edições 70, 2011.

BRASIL. Ministério da Saúde. Secretaria de Vigilância em Saúde. Boletim Epidemiológico de Sífilis, Brasília, ano 5, n. 1, out. 2019a. Disponível em: 
https://portalarquivos2.saude.gov.br/images/pdf/2019/outubro/30/Boletim-S--filis-2019internet.pdf. Acesso em: 10 nov. 2019.

BRASIL. Ministério da Saúde. Sífilis: o que é, causas, sintomas, tratamento, diagnóstico e prevenção. Brasília, 2019b. Disponível em: https://antigo.saude.gov.br/saude-de-az/sifilis\#: :text=A\%20s\%C3\%ADfilis\%20\%C3\%A9\%20uma\%20Infec\%C3\%A7\%C3\%A3o, secund \%C3\%A1ria\%2C\%20latente\%20e\%20terci\%C3\%A1ria. Acesso em: 10 nov. 2019.

BRASIL. Ministério da saúde. Sífilis não. [Brasília], [2018]. Disponível em: https://www.sifilisnao.com.br. Acesso em: 10 nov. 2019.

BRASIL. Poder Legislativo. Lei no 3.987, de 2 de janeiro de 1920. Reorganiza os serviços da Saúde Pública. Diário Oficial da União, Rio de Janeiro, 8 jan. 1920, Seção 1, p. 437. Disponível em: https://www2.camara.leg.br/legin/fed/lei/1920-1929/lei-3987-2-janeiro-1920570495-norma-pl.html. Acesso em: 18 de set. 2020.

CARRARA, Sérgio. A geopolítica simbólica da sífilis: um ensaio de antropologia histórica. História, Ciências, Saúde - Manguinhos, Rio de Janeiro, v. 3, n. 3, p. 391-408, fev. 1997. Disponível em: http://www.scielo.br/pdf/hcsm/v3n3/v3n3a02.pdf. Acesso em:10 set. 2020.

CARRARA, Sérgio. Tributo a Vênus: a luta contra a sífilis no Brasil, da passagem do século aos anos 40. Rio de Janeiro: Editora Fiocruz, 1996.

FIGUEIREDO, Mayanne; CAVALCANTE, Edilma; OLIVEIRA, Célida; MONTEIRO, Maria de Fátima; QUIRINO, Glauberto; OLIVEIRA, Dayanne. Percepção de enfermeiros sobre a adesão ao tratamento dos parceiros de gestantes com sífilis. Rev Rene., Crato, v.16, n. 3, p. 345-354 maio-jun. 2015. Disponível em: http://periodicos.ufc.br/rene/article/view/2789. Acesso em: 27 set. 2020.

FLECK, Ludwik. Gênese e desenvolvimento de um fato científico. Belo Horizonte: Fabrefactum, 2010.

FOUCAULT, Michel. O nascimento da medicina social. In: Microfísica do poder. 18. ed. Rio de Janeiro: Graal, 1979. p. 193-207.

FOUCAULT, Michel. O nascimento da biopolítica: curso dado no Collège de France (1978/1979). São Paulo: Martins Fontes, 2008.

FUNDAÇÃO OSWALDO CRUZ. Casa de Oswaldo Cruz. Departamento de Arquivo e Documentação. Fundo Renato Kehl: inventário. Rio de Janeiro: Fiocruz, 2009.

GOMES, Ordival. Cassiano. História da medicina no Brasil do século XVI. Rio de Janeiro: Instituto Brasileiro de História da Medicina, 1974. 
GONTIJO, Gabriel; ANTONIO, João Roberto. O segundo século: as grandes veredas de uma sociedade centenária. Rio de Janeiro: Sociedade Brasileira de Dermatologia, 2016. Disponível em: https://issuu.com/sbd.br/docs/livro-seg-seculo-da-sbd/125. Acesso em: 27 set. 2020.

MIRANDA, Carlos Alberto Cunha. A arte de curar nos tempos da colônia: limites e espaços da cura. 3. ed. rev. ampl. e atual. Recife: Ed. Universitária da UFPE, 2017.

SANTOS FILHO, Licurgo. História geral da medicina brasileira. São Paulo: Hucitec, 1991, v. 1.

SARACENI, Valéria; LEAL, Maria do Carmo; HARTZ, Zulmira Maria de Araújo. Avaliação de campanhas de saúde com ênfase na sífilis congênita: uma revisão sistemática. Revista

Brasileira de Saúde Materno Infantil, Recife, v. 5, n. 3, p. 263-273, jul.-set. 2005.

Disponível em: http://www.scielo.br/pdf/rbsmi/v5n3/a02v5n3.pdf. Acesso em: 10. nov. 2019.

UJVARI, Stephan Cunha. História da humanidade contada pelo vírus. São Paulo: Contexto, 2008.

Submetido em: 30.09.2020.

Aprovado em: 11.11.2020. 